\title{
MicroRNA-27a inhibitors alone or in combination with perifosine suppress the growth of gastric cancer cells
}

\author{
DONGXIAO LIU ${ }^{1 *}$, QINGMIN SUN ${ }^{2 *}$, SONG LIANG $^{3^{*}}$, LINLIN XU $^{4}$, XUAN LUO $^{4}$, \\ XIAOMEI ZHAO ${ }^{4}$, XUERONG WANG $^{4}$ and LI YANG $^{3}$
}

${ }^{1}$ Department of General Surgery, The Second Affiliated Hospital of South-east University, The Second Hospital of Nanjing, Nanjing 210003; ${ }^{2}$ Department of Pharmacy, Affiliated Hospital of Nanjing University of Chinese Medicine, Nanjing 210029;

${ }^{3}$ Department of General Surgery, The First Affiliated Hospital of Nanjing Medical University;

${ }^{4}$ Department of Pharmacology, Nanjing Medical University, Nanjing 210029, P.R. China

Received July 18, 2012; Accepted November 12, 2012

DOI: $10.3892 / \mathrm{mmr} .2012 .1191$

\begin{abstract}
MicroR NA-27a (miR-27a) is an oncogene that contributes to drug resistance in various types of cancer. However, the involvement of miR-27a in gastric cancer has yet to be elucidated. Perifosine is an alkylphospholipid exhibiting antitumor activity as shown in both preclinical studies and clinical trials. The effects of perifosine on gastric cancer have yet to be determined. Therefore, this study was conducted to detect the role of miR-27a and perifosine in human gastric cancer. miR-27a was found to be expressed in human gastric cancer tissues and cell lines by quantitative reverse-transcription polymerase chain reaction (qRT-PCR). The correlation between miR-27a expression and clinicopathological characteristics of gastric cancer. We also explored the growth inhibitory effect of perifosine on human gastric cancer cells with or without co-targeting miR-27a by sulforhodamine B (SRB) assay. The results showed that miR-27a expression was significantly upregulated in gastric cancer tissues, compared with their non-tumor adjacent tissues. High expression levels of miR-27a were associated with poor tumor histological grade $(\mathrm{P}=0.037)$. MiR-27a inhibitors suppressed the growth of MGC-803 cells. Assay results showed that perifosine exerted its activity selectively on the AGS cell line and the growth inhibitory effect of perifosine was enhanced significantly in combination with miR-27a inhibitors in MGC-803 cells. In
\end{abstract}

Correspondence to: Professor Li Yang, Department of General Surgery, The First Affiliated Hospital of Nanjing Medical University, 300 Guangzhou Road, Nanjing 210029, Jiangsu, P.R. China

E-mail: pwkyangli@yahoo.com.cn

Professor Xuerong Wang, Department of Pharmacology, Nanjing Medical University, Nanjing 210029, Jiangsu, P.R. China

E-mail: wangxrnj@gmail.com

*Contributed equally

Key words: microRNA-27a, gastric cancer, perifosine, combination therapy conclusion, our results demonstrated that miR-27a may be a therapeutic target and potential prognostic biological marker in gastric cancer. MiR-27a inhibitors alone or in combination with perifosine may be a novel therapeutic approach against gastric cancer.

\section{Introduction}

Gastric cancer remains the second leading cause of cancer-related mortality worldwide $(1,2)$. Even after a curative resection alone or after chemotherapy, more than $50 \%$ of patients are likely to experience local regional recurrence $(3,4)$. Despite the development of more diagnostic techniques and new treatment modalities, the five-year survival rate of gastric cancer has not significantly changed. Therefore, it is critical to explore more specific and efficient therapies.

MicroRNAs (miRNAs) are important post-transcriptional regulators of gene expression. Additionally, they are a class of highly conserved, small RNA molecules that regulate key biological processes, including differentiation, development, proliferation and metabolism (5). Accumulating evidence suggests that the dysregulation of miRNAs expression contributed to malignant transformation. Furthermore, miRNAs have been confirmed to act as oncogenes or tumor suppressors in many types of cancer (6). miRNAs, such as miR-130a, miR-214, miR-27a and miR-451, have been reported to be associated with chemotherapy resistance (7-9). In particular, miR-27a, an oncogene, was found to be widely expressed in breast cancer, gastric adenocarcinoma, human uveal melanoma and colon cancer (10-13) and to contribute to drug resistance in various types of cancer (14-17). However, the role of miR-27a in gastric cancer remains to be determined.

Perifosine is an orally bioavailable alkylphospholipid exhibiting antitumor activity in both preclinical models and clinical trials $(18,19)$. Its anticancer activity is known to target the cell membrane, inhibit Akt activity, and affect cell processes such as growth arrest, apoptosis and survival. In the preclinical studies, perifosine combined with UCN-01, the chemotherapeutic agent etoposide and other antitumor agents shows synergistic antitumor effects $(20,21)$. In the clinical trials, perifosine shows substantial antitumor activity in sarcoma and 
renal cell carcinoma (22). Combined with dexamethasone, it also has activity in relapsed/refractory multiple myeloma (23). However, the growth inhibitory effect of perifosine on gastric cancer has yet to be reported. Moreover, no related studies on the effect of combining miR-27a inhibitors with perifosine on gastric cancer are currently available.

Therefore, we hypothesized that miR-27a was an oncogene in gastric cancer and that miR-27a inhibitors or perifosine were able to suppress gastric cancer cell growth. In the present study, miR-27a expression was detected in gastric cancer tissues, their matched non-tumor adjacent tissues and gastric cancer cell lines. We also investigated the effect of miR-27a inhibitors or perifosine on human gastric cancer cell growth in vitro.

\section{Materials and methods}

Reagents. Perifosine was supplied by Selleck Chemicals LLC (Houston, TX, USA). This agent was dissolved in phosphate-buffered saline (PBS) and stored at $-20^{\circ} \mathrm{C}$. Stock solution was diluted to the appropriate concentrations with growth medium immediately before use.

Human tissue samples. In total, 67 pairs of human gastric tissue samples were obtained during surgery and used after informed consent was obtained from all 67 patients. The patients underwent surgical resection at the First Affiliated Hospital of Nanjing Medical University between 2009 and 2010 following diagnosis of gastric cancer based on histopathological evaluation. The matched non-tumor adjacent tissues were obtained from a segment of the resected specimens that was at a distance from the tumor $(>5 \mathrm{~cm})$. The samples were snap-frozen in liquid nitrogen and stored at $-80^{\circ} \mathrm{C}$. No local or systemic treatment was conducted in these patients prior to surgery. The tumor histological grade was assessed according to World Health Organization criteria and was staged using the TNM staging of the International Union Against Cancer (UICC)/American Joint Committee on Cancer (AJCC) system (2002). The study was approved by the Research Ethics Committee of Nanjing Medical University, China. Sample data, including age, gender, weight, residence, hypertension, diabetes, smoke, tumor location, histological grade, depth of tumor invasion, lymph node metastasis and clinical stage were obtained from the clinical and pathologic records (Table I).

Cell lines and cell culture. The human gastric cancer cell lines (AGS and MGC-803) were obtained from the Shanghai Institutes for Biological Sciences, Chinese Academy of Sciences (Shanghai, China). The cells were cultured in RPMI-1640 medium (Invitrogen Life Technologies Inc., Carlsbad, CA, USA) supplemented with $10 \%$ fetal bovine serum (Gibco BRL, Grand Island, NY, USA) at $37^{\circ} \mathrm{C}$ in a humidified atmosphere consisting of $5 \% \mathrm{CO}_{2}$.

miRNA transfection. Cells in the exponential phase of growth were plated in $60-\mathrm{mm}$ plates at $1 \times 10^{6}$ cells/plate and cultured for $16 \mathrm{~h}$, and then transfected with miR-27a inhibitors or the negative control (NC) $(100 \mathrm{nM})$ using Lipofectamine ${ }^{\mathrm{TM}}$ 2000 Reagent and OPTI-MEM I reduced serum medium
(Invitrogen Life Technologies Inc.), following the manufacturer's protocol. The effects of miR-27a inhibitors or the $\mathrm{NC}$ were examined $48 \mathrm{~h}$ following transfection as described previously (9).

Growth inhibition assay. Cells were seeded in 96-well culture plates and treated on the second day with perifosine. At the end of a three-day treatment, the cell number was estimated by the sulforhodamine B (SRB) assay, as previously described (24).

RNA isolation and quantitative RT-PCR. Total RNA from specimens and cultured AGS and MGC-803 cells was extracted using TRIzol reagent (Invitrogen Life Technologies Inc.) according to the manufacturer's protocol. TaqMan microRNA assays (Applied Biosystems Inc., Carlsbad, CA, USA) were used to quantify miR-27a expression. Small nuclear RNA, U6B (Applied Biosystems Inc.), was treated as the normalization control. Real-time amplifications were measured in triplicate and performed with the ABI Prism ${ }^{\circledR} 7300$ sequence detection system (Applied Biosystems Inc.). The fold-change of miR-27a was calculated using the $2^{-\Delta \Delta C T}$ method. Therefore, the value of the relative expression ratio $>1.0$ was considered as a high expression as compared to the non-tumor control where a ratio $<1.0$ was considered as a low expression of cancer.

Statistical analysis. Data were presented as the mean \pm SD from at least three separate experiments. Statistical analysis was performed with the Student's t-test and Pearson's $\chi^{2}$ test. The difference between the groups was determined by the one-way analysis of variance (ANOVA). Differences were considered statistically significant at $\mathrm{P}<0.05$. The analyses were carried out with the SPSS 13.0 (SPSS Inc., Chicago, IL, USA) and were based on two-tailed probability.

\section{Results}

Expression of miR-27a in gastric cancer tissues and its correlation with clinicopathological characteristics of gastric cancer. Using a qRT-PCR method, miR-27a was detected in all $67(100 \%)$ pairs of gastric cancer tissues and their matched non-tumor adjacent tissues. Of the 67 patients with gastric cancer, $42(62.69 \%)$ cases revealed $>50 \%$ increase in the miR-27a level as compared to their matched non-tumor adjacent tissues (Fig. 1).

The correlation between miR-27a expression and clinicopathological characteristics of gastric cancer was examined. The Pearson's $\chi^{2}$ test revealed that the expression levels of miR-27a were associated with tumor histological grade $(\mathrm{P}=0.037)$ in gastric cancer patients (Table I). The patients with a high miR-27a expression tended to have a poor tumor histological grade.

Effect of downregulation of miR-27a on cell growth in vitro. The potential involvement of miR-27a in tumorigenesis was determined following the significant increase of miR-27a expression in gastric cancer samples. As an initial step, we examined the expression of miR-27a by qRT-PCR $48 \mathrm{~h}$ following transfection with miR-27a inhibitors or their respective NCs in MGC-803 and AGS cell lines. As shown in Fig. 2A and B, miR-27a inhibitors significantly inhibited 
Table I. miR-27a expression and clinicopathological factors.

\begin{tabular}{|c|c|c|c|c|c|}
\hline \multirow[b]{2}{*}{ Factors } & \multicolumn{2}{|c|}{ High expression group $(n=42)$} & \multicolumn{2}{|c|}{ Low expression group $(n=25)$} & \multirow[b]{2}{*}{ P-value } \\
\hline & $\mathrm{N}$ & Percentage & $\mathrm{N}$ & Percentage & \\
\hline Age $($ mean $\pm \mathrm{SD})$ & \multicolumn{2}{|c|}{$57.71 \pm 11.81$} & \multicolumn{2}{|c|}{$65.76 \pm 9.62$} & \\
\hline Weight (mean \pm SD) & \multicolumn{2}{|c|}{$62.85 \pm 10.87$} & \multicolumn{2}{|c|}{$65.33 \pm 15.21$} & \\
\hline \multicolumn{6}{|l|}{ Gender } \\
\hline Male & 30 & 71.4 & 21 & 84.0 & 0.243 \\
\hline Female & 12 & 28.6 & 4 & 16.0 & \\
\hline \multicolumn{6}{|l|}{ Hypertension } \\
\hline Absent & 31 & 73.8 & 18 & 72.0 & 0.872 \\
\hline Present & 11 & 26.2 & 7 & 28.0 & \\
\hline \multicolumn{6}{|l|}{ Diabetes } \\
\hline Absent & 38 & 90.5 & 23 & 92.0 & 0.833 \\
\hline Present & 4 & 9.5 & 2 & 8.0 & \\
\hline \multicolumn{6}{|l|}{ Smoke } \\
\hline Absent & 26 & 61.9 & 16 & 64.0 & 0.864 \\
\hline Present & 16 & 38.1 & 9 & 36.0 & \\
\hline \multicolumn{6}{|l|}{ Location } \\
\hline Cardia, fundus & 23 & 54.8 & 9 & 36.0 & 0.137 \\
\hline Others & 19 & 45.2 & 16 & 64.0 & \\
\hline \multicolumn{6}{|l|}{ Histological grade } \\
\hline Well, moderately & 25 & 59.5 & 21 & 84.0 & $0.037^{\mathrm{a}}$ \\
\hline Poorly, others & 17 & 40.5 & 4 & 16.0 & \\
\hline \multicolumn{6}{|c|}{ Depth of tumor invasion } \\
\hline $\mathrm{m}, \mathrm{sm}, \mathrm{mp}$ & 6 & 14.3 & 4 & 16.0 & 0.849 \\
\hline ss, se, si & 33 & 85.7 & 21 & 84.0 & \\
\hline \multicolumn{6}{|c|}{ Lymph node metastasis } \\
\hline Absent & 9 & 21.4 & 5 & 32.0 & 0.905 \\
\hline Present & 33 & 78.6 & 17 & 68.0 & \\
\hline \multicolumn{6}{|l|}{ Clinical stage } \\
\hline $\mathrm{I}, \mathrm{II}$ & 10 & 23.8 & 10 & 40.0 & 0.161 \\
\hline $\mathrm{III}, \mathrm{V}$ & 32 & 76.2 & 15 & 60.0 & \\
\hline \multicolumn{6}{|l|}{ Residence } \\
\hline Rural & 23 & 54.8 & 9 & 36.0 & 0.137 \\
\hline Urban & 19 & 45.2 & 16 & 64.0 & \\
\hline
\end{tabular}

${ }^{a}$ Indicated statistical significance $(\mathrm{P}<0.05)$; m, mucosa; sm, submucosa; mp, muscularis propria; ss, subserosa; se, penetration of serosa; si, invasion of adjacent strucures.

the expression of miR-27a by 94.22 and $99.78 \%$ as compared with NCs in MGC-803 and AGS cells, respectively. According to the results of the SRB assay and growth curves, the MGC-803 cell line, which was transiently transfected with miR-27a inhibitors, was found to have a significant growth inhibition as compared with $\mathrm{NC}(\mathrm{P}=0.005$, Fig. $2 \mathrm{C})$. On day 5, the cell number decreased to 0.57 -fold in cells expressing the downregulation of miR-27a. However, this decrease in cell number did not suppress the growth of AGS cells $(\mathrm{P}=0.766$, Fig. 2D). These findings suggest that the downregulation of miR-27a selectively inhibited cell growth in MGC-803 cells.
Expression of miR-27a in gastric cancer cell lines and the effect of perifosine. To explain the above finding, we detected the expression level of miR-27a in MGC-803 and AGS gastric cancer cell lines. Compared with AGS cells, the expression level of miR-27a was increased in MGC-803 cells (2.67 \pm 0.18 -fold, Fig. 3A). These data suggest that the selective sensitivity of MGC-803 cells to miR-27a inhibitors is likely to be correlated with the high miR-27a expression levels.

In this study, the effect of perifosine as a single agent on the growth of the MGC-803 and AGS cells was investigated for the first time. Subsequent to treatment with varying 


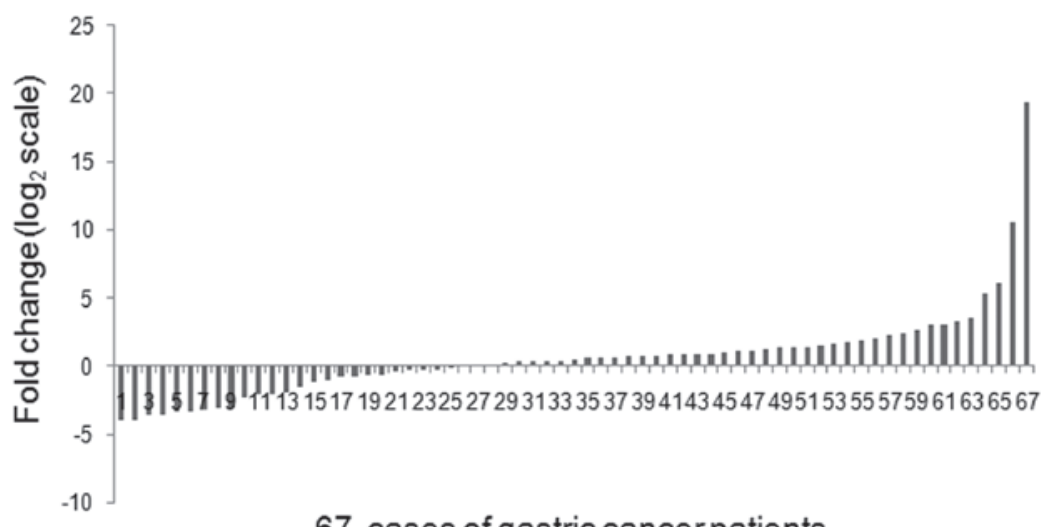

Figure 1. The expression of miR-27a in gastric cancer tissues. MiR-27a was detected in gastric cancer patients by quantitative real-time PCR. Data were

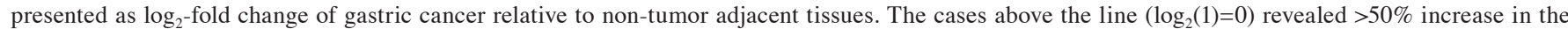
miR-27a level.

A

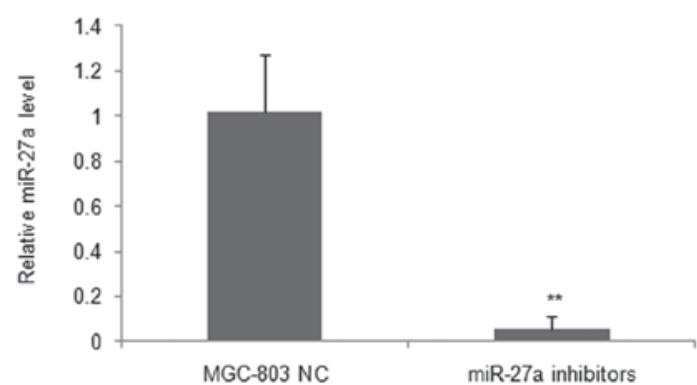

C

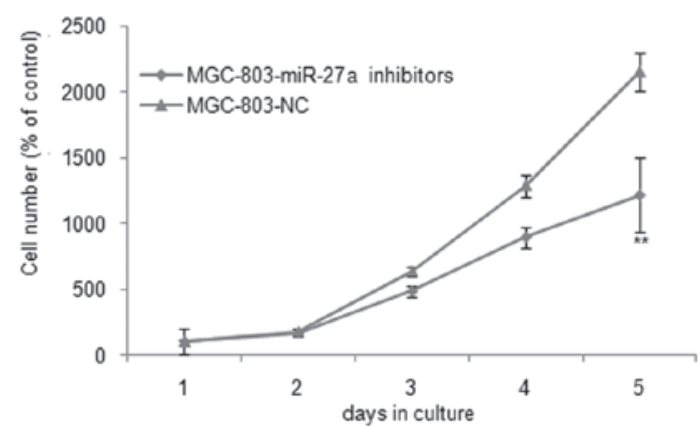

B

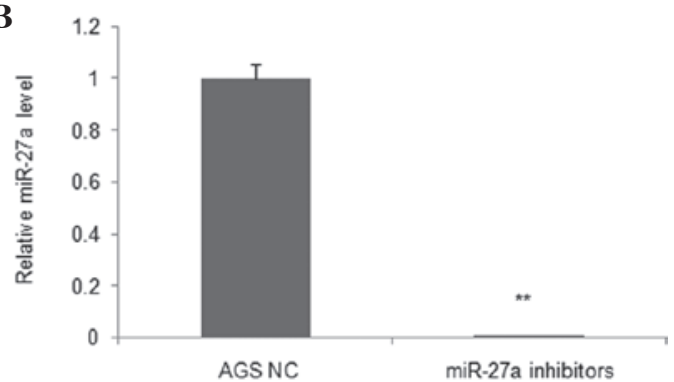

D

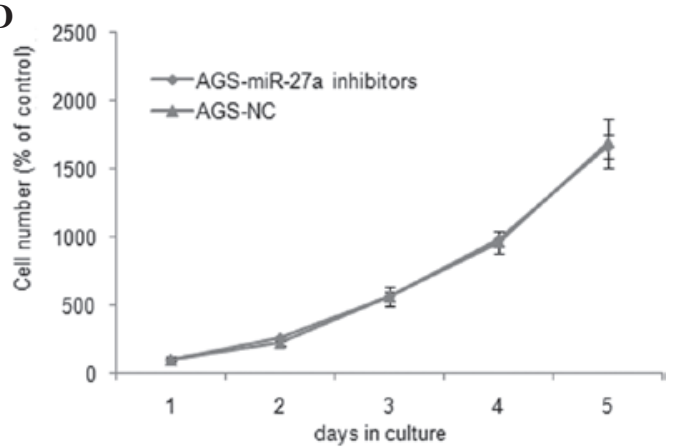

Figure 2. Downregulation of miR-27a inhibits cell proliferation in vitro. (A and B) Relative level of miR-27a in the MGC-803 and AGS cell lines following transfection of miR-27a inhibitors. Total cell RNA extracted from each group was examined by quantitative real-time PCR. (C and D) MGC-803 and AGS cell lines were transfected with miR-27a inhibitors or negative controls (NCs). Cells were subjected to SRB assay to estimate cell viability. Each point is the mean \pm SD. Results were reproducible in three independent experiments. ${ }^{* *} \mathrm{P}<0.01$.

concentrations of perifosine for $72 \mathrm{~h}$, the results of SRB assay showed that perifosine decreased MGC-803 and AGS cell growth by $52.44 \pm 2.50$ and $74.72 \pm 0.29 \%$ in $10 \mu \mathrm{M} / 1$ group compared to control cells, respectively (Fig. 3B). Additionally, the $50 \%$ inhibitory concentration $\left(\mathrm{IC}_{50}\right)$ values of perifosine in MGC-803 and AGS cells were 9.84 and $2.76 \mu \mathrm{M} / 1$, respectively, for the same intervals. These results suggest that perifosine inhibited the growth of gastric cancer cells in a dose-dependent manner, but AGS cells were more sensitive to perifosine compared to MGC-803 cells. We hypothesized that the insensitivity of MGC-803 cells to perifosine may also be correlated with the high miR-27a expression levels and that the downregulation of miR-27a may enhance the effects of perifosine on MGC-803 cells.
Growth inhibitory effect of perifosine following transfection with miR-27a inhibitors. To confirm that perifosine insensitivity is correlated with miR-27a expression in MGC-803 cells, cells were transfected with either the miR-27a inhibitors or the $\mathrm{NC}$ and treated with varying concentrations of perifosine. Cell viability was then measured using the SRB assay. As shown in Fig. 4 , at the maximum concentration of $10 \mu \mathrm{M} / 1$ perifosine, the cell viability of the MGC-803 cells with miR-27a transfection was reduced by $60.53 \pm 1.99 \%$, whereas the NC-transfected cell viability was reduced by $50.04 \pm 1.17 \%$. The $\mathrm{IC}_{50}$ of perifosine was 4.93 and $9.21 \mu \mathrm{M} / 1$ in MGC-803 cells with miR-27a inhibitors and the NC-transfected cells, respectively (Fig. 4). The $\mathrm{IC}_{50}$ of perifosine was significantly decreased after miR-27a inhibitor transfection $(\mathrm{P}<0.001)$. These data suggest 

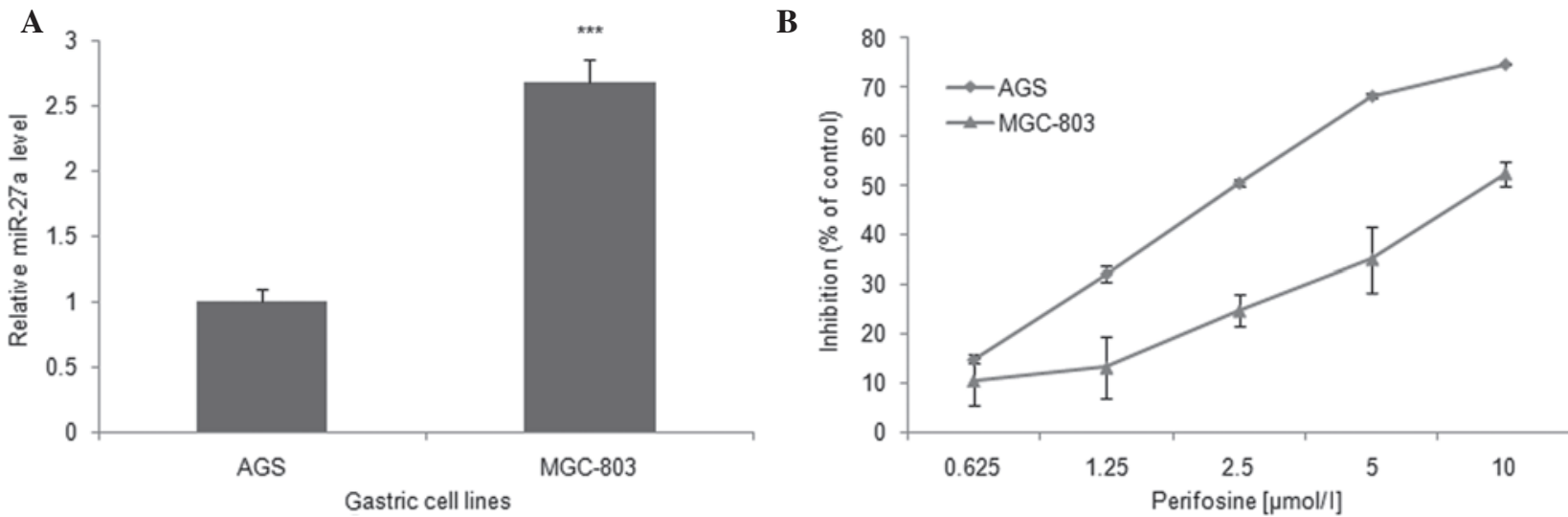

Figure 3. Effect of perifosine on human gastric cancer cell growth and the expression of miR-27a. (A) The relative expression of miR-27a was determined by normalization to U6B control using quantitative real-time PCR in the MGC-803 gastric cancer cell line as compared to AGS. Each point is the mean \pm SD Results were reproducible in three independent experiments. ${ }^{* * *} \mathrm{P}<0.001$. (B) Survival of AGS and MGC-803 cells was determined by sulforhodamine B (SRB) assay after $72 \mathrm{~h}$ stimulation with or without varying concentrations of perifosine. Each point is the mean $\pm \mathrm{SD}$. Results were reproducible in three independent experiments.

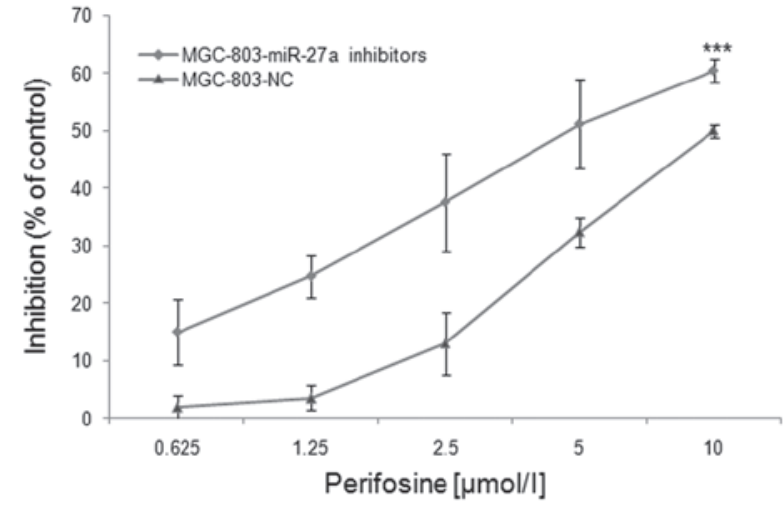

Figure 4 . The growth inhibitory effect of perifosine following transfection with miR-27a inhibitors. MGC-803 cells with miR-27a inhibitors or negative control (NC)-transfected cells were treated with varying concentrations of perifosine ranging from 0.625 to $10 \mu \mathrm{M} / 1$. After $72 \mathrm{~h}$, the cells were subjected to SRB assay to estimate cell viability. Each point is the mean \pm SD. Results were reproducible in three independent experiments. ${ }^{* * *} \mathrm{P}<0.001$.

the downregulation of miR-27a enhanced the inhibitory effects of perifosine on gastric cancer MGC-803 cells.

\section{Discussion}

It is well known that surgical resection is the most effective treatment for gastric cancer and is effective in prolonging the survival of patients with early gastric cancer, whereas the prognosis for individuals with advanced gastric cancer remains poor (25). Although numerous chemotherapy drugs have been studied, there is no internationally recognized standard of care for chemotherapy strategy (26). Therefore, new therapeutic approaches should be developed.

MiRNAs are important post-transcriptional regulators of gene expression. Moreover, they are a class of highly conserved, small RNA molecules that regulate key biological processes, while the dysregulation of miRNA expression contributes to malignant transformation $(5,6)$. Recent evidence shows that the dysregulation of miRNAs may be important in cancer initiation, progression and prognosis $(27,28)$. Therefore, the study of their clinical potential in gastric cancer is imperative.

MiR-27a, which is considered to be a carcinogenesis, has been found to be widely expressed in many tumors (10-13). Liu et al (12) have shown that miR-27a was upregulated in human gastric adenocarcinoma and MGC-803 gastric cancer cells. In this study, we found a significant high expression of miR-27a in gastric cancer tissues compared with their matched non-tumor adjacent tissues, which was consistent with previous reports (12). Taken together, we have further suggested that miR-27a may be involved in carcinogenesis as an oncogene in human gastric cancer. Furthermore, miR-27a expression was associated with tumor histological grade $(\mathrm{P}=0.037)$ in gastric cancer patients. The patients with a high miR-27a expression tended to have a poor tumor histological grade, which was an independent prognostic factor in patients with cancer. Additionally, miR-27a may be involved in gastric cancer progression and serve as a potential prognostic marker for gastric cancer patients.

The correlation of cell growth and the expression of miR-27a was detected. In present experiments, we transfected MGC-803 and AGS cells with the miR-27a inhibitors or the NCs and yielded a high transfection efficiency. Moreover, results of the SRB assay revealed that the downregulation of miR-27a significantly inhibited cell growth in the MGC-803 cell line, but did not suppress the growth of AGS cells. The reason for the downregulation of miR-27a inhibiting cell growth of MGC-803 versus AGS cells was also investigated, and the results suggest varying miR-27a expression levels. Our findings also confirmed that the expression of miR-27a was higher in the MGC-803 cell line as compared to the AGS cell line. Thus, miR-27a acts as an oncogene in gastric cancer and downregulation of its expression significantly inhibited gastric cancer cell growth. However, the lack of a significant effect on AGS cells may be due to the low miR-27a expression levels.

Perifosine is a synthetic, orally bioavailable alkylphospholipid analogue that acts primarily at the cell membrane targeting signal transduction pathways. Perifosine has been shown to exert anticancer activity, which is partly associated with its ability to inhibit Akt activity and the mTOR signaling 
pathway, and to affect multiple cell processes, including proliferation, survival and apoptosis $(19,29,30)$. Perifosine has recently received wide attention due to its potential health beneficial effects (31). Therefore, to improve our understanding of the antitumor activity of perifosine, we measured its effects on human gastric cancer cells. Results of the present study have shown for the first time that perifosine inhibited human gastric cancer cell growth in vitro in a concentration-dependent manner. However, perifosine exerted its activity selectively on AGS cells, which is a miR-27a low expression gastric cancer cell line. These data therefore suggest that the insensitivity of perifosine is correlated with the high expression levels of miR-27a in gastric cancer cell lines.

In their study, Zhu et al (9) reported that miR-27a and miR-451 were involved in activating the multidrug resistant gene 1 (MDR1) P-glycoprotein expression, which was associated with cancer cell resistance to a series of chemotherapeutics. Zhang et al (15) also reported that the downregulation of miR-27a has the potential to reverse MDR of esophageal squamous cell carcinoma. Additionally, the mechanism is likely to decrease the expression of P-glycoprotein, Bcl-2, and the transcription of MDR1, but upregulate the expression of Bax. Notably, the growth inhibitory effect of perifosine was enhanced when combined with miR-27a inhibitors. The result of SRB assay indicated that the downregulation of miR-27a promoted perifosine sensitivity of the MGC-803 cell line, in which miR-27a expression was higher than that in AGS cell line. This finding may be partly due to the fact that miR-27a was associated with chemotherapy resistance and that downregulation of miR-27a modulated MDR in cancer cells. Taken together, $\mathrm{miR}-27 \mathrm{a}$ is able to potentially participate in the establishment of a drug-resistant network of perifosine in gastric cancer. Co-targeting the miR-27a might provide a new therapy to increase chemotherapy sensitivity, with the possible mechanism being that the downregulation of miR-27a was capable of significantly decreasing the expression of P-glycoprotein, which functioned as an ATP-dependent drug-efflux pump (15).

In conclusion, miR-27a is an oncogene in gastric cancer whose downregulation has the potential to inhibit the growth of MGC-803 cells in vitro. Moreover, a high miR-27a expression has been associated with poor tumor histological grade in gastric cancer patients. Furthermore, our study has demonstrated for the first time that perifosine exerts growth inhibitory activities in gastric cancer cells in vitro, and that the downregulation of miR-27a may significantly increase the growth inhibitory effect of perifosine. Therefore, miR-27a may be a therapeutic target and potential prognostic biological marker in gastric cancer. MiR-27a inhibitors alone or in combination with perifosine may be a novel therapeutic approach against gastric cancer. However, more investigations should be conduced to clarify the mechanism underlying the correlation between the miR-27a and tumor chemoprevention of perifosine.

\section{Acknowledgements}

This study was supported by the following grants: 'Medical ZhongDianRenCai Project' of Jiangsu (RC2011059), '333 Project', 'Six RenCai Gaofeng' Funding for the Young Academic Leader of Jiangsu to LY National Natural Science
Foundation of China (nos. 30873099 and 81001444), and the Science \& Technology Development Project of Nanjing (nos. 201201055, 2012YX001).

\section{References}

1. Pisani P, Parkin DM, Bray F and Ferlay J: Erratum: estimates of the worldwide mortality from 25 cancers in 1990. Int J Cancer 83: 870-873, 1999.

2. Danaei G, Vander Hoorn S, Lopez AD, Murray CJ and Ezzati M: Causes of cancer in the world: comparative risk assessment of nine behavioural and environmental risk factors. Lancet 366 : 1784-1793, 2005 .

3. Orditura M, De Vita F, Muto P, et al: Adjuvant chemoradiotherapy in patients with stage III or IV radically resected gastric cancer: a pilot study. Arch Surg 145: 233-238, 2010.

4. Milne AN, Carneiro F, O'Morain C and Offerhaus GJ: Nature meets nurture: molecular genetics of gastric cancer. Hum Genet 126: 615-628, 2009.

5. Dykxhoorn DM: MicroRNAs and metastasis: little RNAs go a long way. Cancer Res 70: 6401-6406, 2010.

6. Croce CM: Causes and consequences of microRNA dysregulation in cancer. Nat Rev Genet 10: 704-714, 2009.

7. Yang H, Kong W, He L, et al: MicroRNA expression profiling in human ovarian cancer: miR-214 induces cell survival and cisplatin resistance by targeting PTEN. Cancer Res 68: 425-433, 2008.

8. Sorrentino A, Liu CG, Addario A, Peschle C, Scambia G and Ferlini C: Role of microRNAs in drug-resistant ovarian cancer cells. Gynecol Oncol 111: 478-486, 2008.

9. Zhu H, Wu H, Liu X, et al: Role of MicroRNA miR-27a and miR-451 in the regulation of MDR1/P-glycoprotein expression in human cancer cells. Biochem Pharmacol 76: 582-588, 2008.

10. Mertens-Talcott SU, Chintharlapalli S, Li X and Safe S: The oncogenic microRNA-27a targets genes that regulate specificity protein transcription factors and the G2-M checkpoint in MDA-MB-231 breast cancer cells. Cancer Res 67: 11001-11011, 2007.

11. Pathi SS, Jutooru I, Chadalapaka G, et al: GT-094, a NO-NSAID, inhibits colon cancer cell growth by activation of a reactive oxygen species-microRNA-27a: ZBTB10-specificity protein pathway. Mol Cancer Res 9: 195-202, 2011.

12. Liu T, Tang H, Lang Y, Liu M and Li X: MicroRNA-27a functions as an oncogene in gastric adenocarcinoma by targeting prohibitin. Cancer Lett 273: 233-242, 2009.

13. Sun Q, Cong R, Yan H, et al: Genistein inhibits growth of human uveal melanoma cells and affects microRNA-27a and target gene expression. Oncol Rep 22: 563-567, 2009.

14. Zhao X, Yang L and Hu J: Down-regulation of miR-27a might inhibit proliferation and drug resistance of gastric cancer cells. J Exp Clin Cancer Res 30: 55, 2011.

15. Zhang $\mathrm{H}, \mathrm{Li}$ M, Han Y, et al: Down-regulation of miR-27a might reverse multidrug resistance of esophageal squamous cell carcinoma. Dig Dis Sci 55: 2545-2551, 2010.

16. Li Z, Hu S, Wang J, et al: MiR-27a modulates MDR1/P-glycoprotein expression by targeting HIPK2 in human ovarian cancer cells. Gynecol Oncol 119: 125-130, 2010.

17. Feng DD, Zhang H, Zhang P, et al: Down-regulated miR-331-5p and miR-27a are associated with chemotherapy resistance and relapse in leukemia. J Cell Mol Med 15: 2164-2175, 2011.

18. Vink SR, Schellens JH, van Blitterswijk WJ and Verheij M: Tumor and normal tissue pharmacokinetics of perifosine, an oral anticancer alkylphospholipid. Invest New Drugs 23: 279-286, 2005.

19. Hilgard P, Klenner T, Stekar J, Nossner G, Kutscher B and Engel J: D-21266, a new heterocyclic alkylphospholipid with antitumour activity. Eur J Cancer 33: 442-446, 1997.

20. Nyakern M, Cappellini A, Mantovani I and Martelli AM: Synergistic induction of apoptosis in human leukemia T cells by the Akt inhibitor perifosine and etoposide through activation of intrinsic and Fas-mediated extrinsic cell death pathways. Mol Cancer Ther 5: 1559-1570, 2006

21. Dasmahapatra GP, Didolkar P, Alley MC, Ghosh S, Sausville EA and Roy KK: In vitro combination treatment with perifosine and UCN-01 demonstrates synergism against prostate (PC-3) and lung (A549) epithelial adenocarcinoma cell lines. Clin Cancer Res 10: 5242-5252, 2004.

22. Van Ummersen L, Binger K, Volkman J, et al: A phase I trial of perifosine (NSC 639966) on a loading dose/maintenance dose schedule in patients with advanced cancer. Clin Cancer Res 10: 7450-7456, 2004. 
23. Richardson PG, Wolf J, Jakubowiak A, et al: Perifosine plus bortezomib and dexamethasone in patients with relapsed/refractory multiple myeloma previously treated with bortezomib: results of a multicenter phase I/II trial. J Clin Oncol 29: 4243-4249, 2011.

24. Papazisis KT, Geromichalos GD, Dimitriadis KA and Kortsaris AH: Optimization of the sulforhodamine B colorimetric assay. J Immunol Methods 208: 151-158, 1997.

25. Ueda T, Volinia S, Okumura H, et al: Relation between microRNA expression and progression and prognosis of gastric cancer: a microRNA expression analysis. Lancet Oncol 11: 136-146, 2010.

26. De Vita F, Giuliani F, Silvestris N, Catalano G, Ciardiello F and Orditura M: Human epidermal growth factor receptor 2 (HER2) in gastric cancer: a new therapeutic target. Cancer Treat Rev 36 Suppl 3: S11-S15, 2010

27. Ruan K, Fang X and Ouyang G: MicroRNAs: novel regulators in the hallmarks of human cancer. Cancer Lett 285: 116-126, 2009.
28. Mirnezami AH, Pickard K, Zhang L, Primrose JN and Packham G: MicroRNAs: key players in carcinogenesis and novel therapeutic targets. Eur J Surg Oncol 35: 339-347, 2009.

29. Vink SR, Lagerwerf S, Mesman E, et al: Radiosensitization of squamous cell carcinoma by the alkylphospholipid perifosine in cell culture and xenografts. Clin Cancer Res 12: 1615-1622, 2006.

30. Momota H, Nerio E and Holland EC: Perifosine inhibits multiple signaling pathways in glial progenitors and cooperates with temozolomide to arrest cell proliferation in gliomas in vivo. Cancer Res 65: 7429-7435, 2005.

31. Gills JJ and Dennis PA: Perifosine: update on a novel Akt inhibitor. Curr Oncol Rep 11: 102-110, 2009. 